\title{
VARIAÇÃO NA EXPRESSÃO DA PRIMEIRA PESSOA DO PLURAL EM TEXTOS DE ALUNOS DO ENSINO FUNDAMENTAL: UMA PROPOSTA PEDAGÓGICA
}

\author{
VARIACIÓN EN LA EXPRESIÓN DE LA PRIMERA PERSONA DE \\ PLURAL EN TEXTOS DE ESTUDIANTES DE ENSENAANZA FUNDAMENTAL: \\ UNA PROPUESTA PEDAGÓGICA
}

\author{
VARIATION IN THE EXPRESSION OF THE FIRST PERSON OF \\ PLURAL IN TEXTS OF STUDENT ELEMENTARY SCHOOL: AN \\ PEDAGOGICAL PROPOSAL
}

Cátia Cilene Pereira Meireles CUNHA ${ }^{1}$ Maricineia Pereira Meireles da SILVA ${ }^{2}$

RESUMO: O presente trabalho investigou as variantes usadas para expressão do $\mathrm{P} 4 \mathrm{em}$ produções de alunos do Fundamental II. Percebeu-se, na aplicação da mediação pedagógica, com foco na variação nós/a gente, que em textos dos gêneros relato de experiência [+oralidade] os alunos manifestaram a prática de escrita da sociedade letrada brasileira alternando o uso de nós/ a gente. Já no gênero relatório [+letramento], o uso da variante tradicional foi semicategórico. Os resultados refletem, por um lado, a desconstrução da crença de que a escrita só aceita a variante canônica e, por outro, o avanço no processo de letramento dos alunos, que passaram a reconhecer os contextos em que as duas variantes de $\mathrm{P} 4$ podem coocorrer e aqueles em que só se admite a variante canônica, de modo que se tornaram capazes de transitar de um ponto a outro do contínuo, a depender do gênero textual em se dá o evento comunicativo.

PALAVRAS-CHAVE: Primeira pessoa do plural (P4). Contínuo de Variação. Letramento.

RESUMEN: El presente trabajo investigó las variantes utilizadas para la expresión de P4 en producciones de estudiantes de Primaria II. En la aplicación de la mediación pedagógica, enfocándose en la variación nosotros / la gente, se notó que en los textos de los géneros reporte de experiencia [+ oralidad] los estudiantes manifestaron la práctica de escritura de la sociedad alfabetizada brasileña, alternando el uso de nosotros / la gente. En el género reporte [+ alfabetización], el uso de la variante tradicional fue semictegorial. Estos resultados reflejan, por un lado, la deconstrucción de la creencia de que la escritura solo acepta la variante canónica y, por otro, el progreso en el proceso de alfabetización de los estudiantes, quien vino a reconocer los

\footnotetext{
${ }^{1}$ Universidade Federal Rural do Rio de Janeiro (UFRRJ), Seropédica - RJ - Brasil. Mestra em Letras. Professora na Rede Estadual do Rio de janeiro. ORCID: https://orcid.org/0000-0001-6081-0660. Email:catiameireles@yahoo.com.br

${ }^{2}$ Centro Universitário de Volta Redonda (UNIFOA), Volta Redonda - RJ - Brasil. Mestrado acadêmico Interdisciplinar em Saúde e Educação. Professora no Centro Universitário de Barra Mansa (UBM). ORCID: https://orcid.org/0000-0003-4413-6551. E-mail: maricineia@uol.com.br
} 
contextos en los que pueden coocurrir las dos variantes de P4 y aquellos en los que solo se permite la variante canónica, de modo que pudieron moverse de un punto a otro del continuo, dependiendo del género textual en el que tiene lugar el evento comunicativo.

PALABRAS CLAVE: Primera persona del plural (P4). Continua de variación. Alfabetización.

ABSTRACT: The present work investigated the variants used for P4 expression in productions of Elementary II students. In the application of pedagogical mediation, focusing on the variation we la gente, it was noticed that in texts of the genres experience report [+ orality] the students manifested the writing practice of the Brazilian literate society, alternating the use of we la gente. In the report genre [+ literacy], the use of the traditional variant was semi-categorical. The results reflect, on the one hand, the deconstruction of the belief that writing only accepts the canonical variant and, on the other hand, the progress in the students' literacy process, because they have come to recognize the contexts in which the two variants of P4 can co-occur and those in which only the canonical variant is admitted, so that they have become able to move from one point to another of the continuum, depending on the textual genre in which the communicative event occurs.

KEYWORDS: First person plural (P4). Variation Continuum. Literacy.

\section{Introdução}

A ciência linguística já vem há bastante tempo evidenciando que a língua não é uniforme, homogênea, mas repleta de variedades dotadas de organização estrutural própria, ou seja, suas respectivas normas. Segundo Faraco (2008), norma, nesse sentido, representa o que é corriqueiro, usual e normal para determinado grupo de falantes. Em outras palavras, os fenômenos linguísticos manifestados nos diferentes componentes gramaticais (fonética, fonologia, morfologia, sintaxe) e também no léxico de uma comunidade de fala constituem a sua norma, que não comporta apenas fenômenos fixos, mas também fenômenos em variação.

Numa sociedade como a brasileira, que habita um país de dimensões continentais, há diferentes normas linguísticas, e cada uma corresponde a uma gramática - uma manifestação estrutural e funcional da língua histórica — que se liga à cultura própria de determinada comunidade de fala. Embora se saiba, conforme afirma Faraco (2008), que a variedade culta é a praticada pelos falantes mais escolarizados e é referendada por agentes padronizadores da sociedade, como a imprensa, a escola, as universidades, a Igreja, entre outras entidades culturais, não se pode negar a existência 
de outras variedades linguísticas na realidade brasileira. Sendo assim, percebemos a necessidade de reconhecê-las ao abordar a descrição dos fatos gramaticais no ensino de Português, de maneira a romper com a ideia de língua homogênea, tal como preconizam os documentos oficiais, como os Parâmetros Curriculares Nacionais (PCN) e a Base Nacional Comum Curricular (BNCC).

Dentre os fenômenos variáveis presentes no Português Brasileiro (doravante PB), há um que é instigante, pois, apesar de muito presente na oralidade da norma culta urbana, ainda não goza de franca aceitação na modalidade escrita, sobretudo a praticada no âmbito escolar: a variação nós/ a gente para a expressão da primeira pessoa do plural ou u P4 . Há autores, como Lopes (2003, 2007), que preferem o termo P4 (quarta pessoa) à tradicional nomenclatura "primeira pessoa do plural”, sob o argumento de que tal pessoa gramatical não seria propriamente o plural de eu $(e u+e u)$, mas sim a expressão de outra realidade (eu + alguém). No entanto, como a praxe escolar faz largo uso da nomenclatura tradicional, neste trabalho tomaremos, por razões práticas, os dois termos como equivalentes.

A seguir alguns exemplos das duas variantes, extraídos da amostra de Omena (1996, p.185) com grifos nossos:

(01) Porque a única coisa que não vai bem é o seguinte: que nós temos aqui uma dificuldade muito grande de colocar a documentação do bar em dia...

(02) Então, a gente tem condição de fazer uma documentação certa, para que eles não tenham o direito de interferir no nosso movimento, entendeu?

Na modalidade oral do PB, o tradicional pronome frequentemente é substituído pela forma, produto de um processo de gramaticalização do nome gente para exprimir a primeira pessoa do plural, de acordo com a afirmação de Omena (2003). A preferência do falante pela forma inovadora, segundo Lopes (1996), se dá pelo fato de ela proporcionar um descompromisso do indivíduo com o discurso, tornando este mais vago e genérico, pois tal variante pode englobar as demais pessoas.

$\mathrm{O}$ crescente uso da forma no PB foi confirmado por diversas pesquisas realizadas no âmbito da Sociolinguística Variacionista, tais como os estudos feitos por Omena (1996, 2003), Lopes (1996, 2003, 2007), Machado (1995), Maia (2003), Rocha 
(2009), Mendonça (2010), Vianna (2011), entre muitos outros pesquisadores por todo o Brasil.

Sabendo que a tradição escolar, chancelada pela sociedade brasileira letrada, prestigia em registros escritos o tradicional pronome <nós> em detrimento do usual , <a gente> presente tanto na fala quanto na escrita, este trabalho justifica-se pela necessidade de desenvolver nos discentes a habilidade de transitar entre os diferentes gêneros textuais escritos, desde os que permitem o uso de ambas as variantes até os que selecionam a forma prestigiada pela gramática tradicional na expressão de $\mathrm{P} 4$, de modo a contextualizar o fenômeno variável num contínuo, aproximando os alunos da efetiva prática de escrita dos brasileiros mais letrados. Para tanto, aplicamos uma mediação pedagógica baseada na teoria dos contínuos de variação segundo Bortoni-Ricardo (2004), modelo teórico que foi formulado para compreender o fenômeno da variação linguística no PB, selecionando dentre eles o contínuo de oralidade-letramento, que se aproxima do contínuo de Marcuschi (2001), em que os diferentes gêneros textuais são situados uma linha imaginária da fala para a escrita. Assim, trabalhamos com os seguintes gêneros organizados no contínuo de oralidade-letramento: relato de experiência e relatório. Os alunos foram convidados então a produzir um texto no primeiro gênero, situado entre a oralidade e o letramento, para posteriormente o converterem no segundo gênero, pertencente ao polo de letramento do contínuo, seguindo para isso algumas das etapas do processo de retextualização segundo Marcuschi (2001).

Por conseguinte, o presente trabalho tem como objetivo geral legar uma contribuição ao ensino de língua portuguesa no que diz respeito à abordagem da variação linguística em sala de aula a partir de um trabalho sistemático com um fenômeno variável, qual seja, a alternância nós/ a gente. Esse propósito busca superar duas práticas docentes opostas na abordagem desse fenômeno: por um lado, a que ignora o pronome, rotulando-o como inadequado a toda forma de expressão escrita; por outro, a que se isenta de qualquer descrição gramatical nas aulas de Língua Portuguesa, deixando de apresentar os contextos de ocorrência de ambas as variantes, sob o pretexto de que ensinar gramática é algo ultrapassado.

Como objetivos específicos, pretendemos o seguinte: (i) apresentar um levantamento das variantes usadas para a representação de $\mathrm{P} 4$ em textos produzidos por alunos do ensino fundamental a partir de gêneros organizados no contínuo de oralidadeletramento (cf. BORTONI-RICARDO, 2004); (ii) favorecer o letramento dos alunos 
envolvidos na pesquisa para que reconheçam os contextos de uso das variantes em cada ponto do contínuo, de modo a desenvolverem a habilidade de transitar de textos representativos do polo de [+ oralidade] aos do polo de [+ letramento].

Como hipótese da pesquisa, postulou-se que, a partir da mediação pedagógica, os alunos envolvidos tomariam consciência da distribuição das variantes candidatas à realização de P4 no contínuo oralidade-letramento, de forma a manifestar em seus textos a prática de escrita da sociedade letrada brasileira: em gêneros textuais não situados no polo de [+ letramento], como o relato de experiência, usariam as duas variantes, mas em gêneros representativos do polo de [+ letramento], como o relatório, selecionariam apenas o pronome canônico.

\section{Revisão Bibliográfica}

\section{A abordagem das gramáticas tradicionais de língua portuguesa}

$\mathrm{Na}$ abordagem feita pelas gramáticas tradicionais, privilegia-se a prescrição de regras a partir de usos de escritores clássicos da Literatura, o que gera um distanciamento em relação à língua que efetivamente é falada. Assim, a descrição das gramáticas tradicionais não considera a heterogeneidade da língua, a interação entre os falantes nem as variações existentes, que passam a ser consideradas como desvios da norma gramatical.

Tradicionalmente, assume-se que os pronomes pessoais do caso reto servem para desempenhar a função de sujeito das orações, e os oblíquos, geralmente para a função de complemento dos verbos. Com o objetivo de investigar a prescrição dada pelas gramáticas tradicionais ao quadro pronominal, demonstrando a abordagem de $\mathrm{P} 4$, foram verificadas três gramáticas de autores consagrados, quais sejam, a Gramática Normativa da Língua Portuguesa, de Rocha Lima (2008 [1972]); a Moderna Gramática Portuguesa, de Evanildo Bechara (2007); a Nova Gramática do Português Contemporâneo, de Celso Cunha e Lindley Cintra (2007 [1985]). Rocha Lima (2008) não elenca em sua gramática o termo como uma das formas de expressão da primeira pessoa do plural, embora reconheça-o como segunda pessoa (P2) ao lado de na listagem de pronomes pessoais das formas retas (p. 316). Nem mesmo em notas de rodapé o autor faz alusão à variação na expressão de $\mathrm{P} 4$ no $\mathrm{PB}$.

Do mesmo modo, Bechara (2007), em sua gramática, exclui do quadro pronominal a forma <a gente>. No entanto, sem poder ignorar o expressivo uso oral da 
forma <a gente> na variedade brasileira do português, ele põe uma observação em fonte diminuta para mencionar a variação que ora estudamos. Segundo o autor, "o uso do substantivo gente precedido de artigo $a$ e em referência a um grupo de pessoas que se inclui na fala, ou a esta sozinha, passa a pronome e se emprega fora da linguagem cerimoniosa" (BECHARA, 2007, p. 166).

O gramático também destaca nessa observação que em ambos os casos o verbo deverá ficar na $3^{\mathrm{a}}$ pessoa do singular e, para exemplificar o adendo, apresenta o seguinte excerto:

(03) É verdade que a gente, às vezes, tem cá as suas birras [AH.4, II, 158].

Dessa maneira, Bechara (2007) confere status de variante desprestigiosa à forma <a gente>, mesmo que seja visível o emprego de tal forma em palestras proferidas por brasileiros letrados, como o próprio gramático em questão, em eventos acadêmicos que, em tese, são momentos cerimoniosos.

Tal como os gramáticos anteriores, os autores Cunha e Cintra (2007) explicitam no quadro pronominal como primeira pessoa do plural apenas <nós>. Esse quadro não contempla a entrada de novos itens linguísticos no paradigma pronominal e, além disso, inclui formas em desuso no português brasileiro contemporâneo. Posteriormente, em uma seção denominada Fórmulas de Representação da $1^{a}$ Pessoa, ao final do estudo dos Pronomes de Tratamento (p.310), os autores colocam o uso de <a gente> como próprio do colóquio normal em substituição tanto de <nós> como de <eu>, salientando que nesses casos o verbo deverá ficar sempre na terceira pessoa do singular. Apesar de os autores citarem no prefácio da obra que almejam descrever o português contemporâneo que considere as variações existentes e que valorize a expressão oral e escrita da língua vigente, registram a forma usual <a gente> como parte do colóquio normal em observação distanciada da seção pertinente ao assunto, isto é, da apresentação do quadro de pronomes retos, de maneira que conferem à forma inovadora status de fenômeno marginal, apesar de seu largo e consagrado uso.

Já as gramáticas científicas (descritivas) ou de orientação linguística propõem-se pesquisar e analisar um conjunto de características próprias de determinada variedade de uma língua. Ao analisarmos o quadro pronominal apresentado em algumas gramáticas descritivas que se ocuparam da variedade culta do PB, encontramos o seguinte: Gramática de usos do português, de Neves (2011), há uma completa invisibilidade da forma <a gente> como P4 e a autora (2011, p. 469-470) ao final da 
exposição sobre os pronomes pessoais, especificamente na subseção 5.6 intitulada " $N a$ linguagem coloquial o sintagma nominal A GENTE é empregado como pronome pessoal" (p.469), explicita que a variação que focamos neste trabalho é uma forma acolhida apenas no colóquio popular.

Da mesma forma a Gramática Houaiss da língua portuguesa, de Azeredo (2008), privilegia os usos típicos da classe letrada brasileira, de maneira que a variedade escolhida como objeto de descrição é a culta, por isso ele mesmo assevera que pretende reportar-se a considerações de ordem normativa (p.26). Em sua descrição morfossintática, o autor cita que os brasileiros empregam <a gente> na oralidade semiformal e informal com um valor genérico ou para referência "dêitica situacionalmente identificada" (AZEREDO, 2008, p. 176).

A Nova Gramática do Português Brasileiro, de Castilho (2010), considera <a gente> apenas no registro informal e reforça que o fenômeno ocorre sobretudo na modalidade oral. Subtende-se que o gramático em questão considera pouco viável a ocorrência da forma <a gente> na fala em situações formais, o que contraria o resultado de várias pesquisas atuais que constataram largo emprego da variante inovadora em registros orais de muitos indivíduos cultos em situações em que se exigiria a variedade de prestígio, tal como palestras de eventos acadêmicos.

Já a Gramática Pedagógica do Português Brasileiro, de Bagno (2011),há a ênfase que, na posição de sujeito do PB contemporâneo, a preferência é pelo termo <a gente>, principalmente por jovens, tendo esse uso se tornado cada vez mais abrangente mesmo em situações mais monitoradas, causando mudanças nas variedades urbanas de prestígio que agora comportam a ascensão de uma nova classe média.

Portanto, há resistência na modalidade escrita padronizadora, mas não na fala culta, independentemente se é informal ou formal.

\section{As pesquisas sociolinguísticas sobre variação Nós/ A gente no PB}

Muitas são as pesquisas sociolinguísticas que se ocuparam do uso da forma em concorrência com na variedade brasileira do português. Uma das primeiras pesquisadoras a investigar a alternância entre pronomes de primeira pessoa do discurso no plural dentro do PB foi Omena $(1986,1996)$.

$\mathrm{O}$ crescente uso da forma <a gente> no $\mathrm{PB}$ foi confirmado por diversas pesquisas realizadas no âmbito da Sociolinguística Variacionista, tais como os estudos 
feitos por Omena (1996, 2003), Lopes (1996, 2003, 2007), Machado (1995), Maia (2003), Rocha (2009), Mendonça (2010), Vianna (2011), entre muitos outros pesquisadores por todo o Brasil.

Podemos perceber que os estudos sociolinguísticos apontaram as seguintes congruências: (i) os falantes jovens usam mais a forma; (ii) as mulheres acolhem mais a inovação na maioria das cidades; (iii) o maior grau de escolaridade não coíbe o uso da forma inovadora. Por outro lado, percebeu-se que há uma variação estável entre a forma tradicional e a forma inovadora não estigmatizada. Infelizmente, as gramáticas normativas que servem de base ao ensino não descrevem o quadro pronominal do PB de acordo com tais pesquisas e desprestigiam o falar usual dos brasileiros.

\section{Orientações oficiais para o ensino e materiais didáticos}

No ensejo de direcionar e encaminhar o fazer pedagógico nas aulas de Língua Portuguesa, as entidades norteadoras da educação no Brasil propõem documentos que propiciem uma educação linguística adequada à nova configuração social do país. Um dos aspectos previstos é o reconhecimento das variações existentes em nossa língua.

No Brasil há uma base que define o conjunto de aprendizagens essenciais a que todos os discentes têm direito na educação básica.Na constituição de 1988 já se destacava que a educação deveria pautar-se a serviço do pleno desenvolvimento da pessoa, seu preparo para o exercício da cidadania e sua qualificação para o trabalho.

Em 1996, a Lei de Diretrizes e Bases da Educação Nacional (LDB) propôs que fosse firmado um acordo com os vários níveis de governo para estabelecer diretrizes e competências capazes de orientar os currículos. Surgiram então, em 1998, os Parâmetros Curriculares Nacionais (PCN) que se tornaram uma referência nacional para a construção de propostas curriculares nas diferentes redes de ensino de todo o Brasil.

Em 2014, o Plano Nacional de Educação instigava a reflexão sobre a necessidade de estabelecer diretrizes pedagógicas para a educação básica e a criação de uma base nacional que orientasse os currículos de todas as unidades da federação, visto que os PCN apenas faziam propostas gerais que eram seguidas de diferentes formas por todo o país. Surge, assim, a Base Nacional Comum Curricular (BNCC), em que torna-se obrigatório em todas as escolas públicas e particulares do país um currículo contendo uma base comum com as principais competências exigidas ao longo do ensino fundamental. 
Os PCN surgiram com a intenção de propor um currículo com referências nacionais comuns ao processo educativo em todas as regiões brasileiras, de maneira que buscasse o respeito às diversidades regionais, culturais e políticas existentes no Brasil. $\mathrm{Na}$ introdução sobre o tema da variação linguística, os PCN destinados ao terceiro e quartos ciclos do Ensino Fundamental postulam que a Língua Portuguesa é composta de muitas variedades e que

O aluno, ao entrar na escola, já sabe pelo menos uma dessas variedades. aquela que aprendeu pelo fato de estar inserido em uma comunidade de falantes. Certamente, ele é capaz de perceber que as formas da língua apresentam variação e que determinadas expressões ou modos de dizer podem ser apropriados para certas circunstâncias, mas não para outras. Sabe, por exemplo, que existem formas mais ou menos delicadas de se dirigir a alguém, falas mais cuidadas e refletidas, falas cerimoniosas. Pode ser que saiba, inclusive, que certos falares são discriminados e, eventualmente, até ter vivido essa experiência. (BRASIL,1998, p. 81-82)

Portanto, há uma clara indicação de que os alunos já entram na escola com a percepção da existência de diferentes variedades da língua. Nesse sentido, encontramos no texto norteador que "o preconceito linguístico, como qualquer outro preconceito, resulta de avaliações subjetivas dos grupos sociais e deve ser combatido com vigor e energia" (BRASIL,1998, p. 82). O aluno precisa perceber que a escrita e a oralidade tidas como formais constituem mais uma variedade linguística, cuja aprendizagem ampliará suas possibilidades de interferência na comunidade em que vive.

As críticas ao ensino tradicional preconceituoso que desprestigiava a oralidade e as variedades não padrão resultaram em esforços para revisar práticas de ensino da língua.Tal esforço de revisão resultou na incorporação dessas ideias por um número significativo de secretarias de educação estaduais e municipais, no estabelecimento de novos currículos e na promoção de cursos de formação e aperfeiçoamento de professores, inclusive a SEEDUC-RJ. No entanto, como os PCN apenas orientavam a composição do currículo sem a obrigatoriedade, muitas diferenças curriculares eram visíveis por todo o país. Surge então a necessidade de uma Base Nacional Comum Curricular (BNCC) que fosse obrigatória em todo o Brasil. O documento é uma referência nacional obrigatória para que escolas públicas e particulares elaborem ou adequem seus currículos objetivando "a promoção de uma educação integral voltada ao acolhimento, reconhecimento e desenvolvimento pleno de todos os estudantes, com respeito às diferenças e enfrentamento à discriminação e ao preconceito". (BRASIL, 
2018, p. 5). Trata-se, portanto, de um documento bem diretivo que coloca de forma clara os componentes curriculares obrigatórios em cada segmento, especificando o que deverá ser estudado e qual competência será trabalhada em determinado conteúdo.

A abordagem da variação linguística para as séries finais do Ensino Fundamental nas aulas de Português, aparece na BNCC na seção que trata das competências específicas de Língua Portuguesa para tal segmento. A orientação é para que o aluno seja levado a compreender a língua como fenômeno cultural, histórico, social, variável, heterogêneo e sensível aos contextos de uso, capaz de construir a identidade de seus usuários e da comunidade a que pertencem. Há também o objetivo de fazer com que o discente, ao entender que há variações linguísticas, seja respeitoso e rejeite o preconceito linguístico, percebendo que em suas interações sociais, deverá “empregar a variedade e o estilo de linguagem adequados à situação comunicativa, ao(s) interlocutor(es) e ao gênero do discurso/gênero textual" (BRASIL, 2018, p. 85).

Da mesma forma que os documentos de âmbito nacional que dispõem sobre o ensino, a Reorientação Curricular (2006), que é um documento oficial da Secretaria de Educação do Estado do Rio de Janeiro (SEEDUC), tem a pretensão de resgatar os pressupostos e orientações dos PCN e embasar-se na Lei de Diretrizes e Bases da Educação Nacional (LDB). visando contemplar as variedades linguísticas que se fazem presentes no PB. Portanto, a orientação oficial da rede estadual é no sentido de um ensino de Português que leve em conta os fenômenos variáveis na descrição da língua, de maneira que isso deve aparecer na prática do professor em sala de aula.

\section{A abordagem da variação linguística nos livros didáticos (LD)}

Apesar das muitas pesquisas sociolinguísticas que revelam a realidade linguística brasileira e das orientações oficiais quanto à abordagem da variação linguística nas aulas de Língua Portuguesa, percebe-se que as coleções de livros didáticos ainda imprimem um cunho tradicional ao abordarem os conteúdos morfossintáticos, suprimindo importantes fenômenos variáveis de suas descrições da língua. Em análise de seis coleções de livros didáticos para Ensino Fundamental com maior preferência e distribuição no PNLD de 2017 através de pesquisa no site do MEC, constatou-se que não há aproveitamento das variações linguísticas nos conteúdos apresentados pelos autores. 
Freire (2016), em pesquisa realizada sobre a variação linguística em coleções para o Ensino Fundamental, também ressalta os mesmos problemas:

[...] percebeu-se que, conquanto as coleções trouxessem capítulos ou seções em algum dos volumes sobre o tema variação linguística, isso não era retomado no restante da obra ou nos demais volumes, de maneira que a descrição de aspectos morfossintáticos da língua pudesse contemplar os fenômenos variáveis[...]. Em vista disso, depreende-se que a presença do tema "variação linguística" se mostra somente como mais um "conteúdo" nas coleções de livros didáticos, a fim de atender formalmente à exigência dos PCN e do PNLD. (FREIRE,2016, p. 14)

Desse modo, conclui-se que ainda há um longo caminho a percorrer para que os fenômenos variáveis tenham um tratamento adequado nos livros didáticos, pois a postura tradicional é oposta ao que preceituam os documentos norteadores do ensino, segundo os quais deve ser abordada a variação linguística, de maneira que as diversas variantes na realização de um fenômeno variável devem ser efetivamente trabalhadas em sala de aula e não somente as prestigiadas no cânon.

\section{Fundamentação teórica}

\section{a sociolinguística variacionista}

Um marco no campo dos estudos sobre a mudança linguística foi explicitado em um congresso organizado na Universidade da Califórnia (Los Angeles) por William Bright na década de 60. O congresso tinha o objetivo de relacionar as variações linguísticas às variações já existentes na sociedade da época. O evento reuniu vários pesquisadores cujos estudos se voltavam para a relação entre linguagem e sociedade. Fizeram-se presentes no evento John Gumperz, Einar Haugen, Dell Hymes, John Fisher, José Pedro Rona e William Labov. (cf. ALKMIM, 2001, p. 28).

Nessa conferência, o linguista americano Willian Labov apresentou sua teoria, que era contrária tanto à abordagem estruturalista de Saussure como à gerativista de Noam Chomsky, que consideravam a língua como uma realidade abstrata, desvinculada de fatores históricos e sociais, conforme recordam Coelho et al. (2015). Sendo assim, há uma ruptura de Labov com a relação estabelecida entre estrutura e sincronia de um lado, e história evolutiva e diacronia de outro, aproximando igualmente a sincronia e a diacronia às noções de estrutura e funcionamento da língua. 
Labov considerou a língua como um sistema heterogêneo que possui regras categóricas ou variáveis. Tais regras variáveis podem ser mais ou menos aplicadas, dependendo do ambiente linguístico ou social. Segundo o pesquisador, as explicações para as escolhas dos falantes por uma ou outra variante linguística são buscadas pelo controle de fatores 51 condicionadores (variáveis independentes) que têm uma natureza probabilística em que são empregadas técnicas quantitativas para a observação das regularidades que regem a variável.

Conforme afirmam Coelho et al. (2015, p. 17) a pesquisa variacionista laboviana trabalha com resultados estatísticos e se ocupa de questões tais como variação e mudança linguística, bilinguismo, contato linguístico, línguas minoritárias, política e planejamento linguístico, entre outras. Esse ramo da ciência linguística se ocupa da relação entre língua e sociedade, bem como do estudo da estrutura e da evolução da linguagem dentro do contexto social da comunidade de fala.

Para Coelho et al. (2015), essa perspectiva laboviana especifica que não há nada nas formas variantes usadas na realização de uma variável linguística que permita afirmar que umas sejam melhores ou mais corretas do que as outras, sendo elas coexistentes para um mesmo significado nas comunidades de fala. Tais variantes estão sujeitas a condicionamentos estruturais e sociais que influenciam seu grau de ocorrência, ou seja, regulam nossa escolha entre uma ou outra variante. O primeiro grupo de condicionamentos, os estruturais ou linguísticos, incluem aspectos relacionados ao contexto estrutural da língua, como a ordem dos constituintes, a categoria das palavras ou as construções envolvidas, além de aspectos semânticos, entre outros. Já os condicionamentos sociais ou extralinguísticos se referem a aspectos sociais, que normalmente incluem o sexo/gênero, o grau de escolaridade e a faixa etária do informante. Em relação ao fenômeno <a gente> e <você>, Coelho et al. (2015) afirmam:

Muitos condicionadores linguísticos se mostraram relevantes nesses estudos. Alguns de natureza sintática, como o preenchimento do sujeito, por exemplo. Tanto resultados de trabalhos sobre a alternância entre nós e a gente como resultados sobre a alternância entre tu e você mostram que os pronomes a gente e você, por se combinarem com verbos na terceira pessoa do singular (a gente foi e você foi), tendem a aparecer com sujeito preenchido, enquanto pronomes nós e tu, quando carregam a marca morfêmica de primeira pessoa do plural e segunda pessoa do singular, respectivamente, vêm preferencialmente com sujeitos nulos. (COELHO et al,2015, p. 61) 
Portanto, a Sociolinguística Variacionista objetiva investigar a variação e a mudança da língua no contexto social da comunidade de fala, partindo do pressuposto de que não há homogeneidade em nenhuma língua, pois as vivências intrínsecas de cada grupo criarão o 52 repertório linguístico que será sempre heterogêneo, de maneira que, caso isso não ocorra, será uma disfunção, uma anomalia.

Segundo Coan e Freitag (2010), a heterogeneidade proclamada por Labov é aquela cuja variação pode ser sistematicamente explicada, ou seja, dois enunciados que se referem ao mesmo estado de coisas com o mesmo valor de verdade constituem-se como variantes de uma mesma variável (regra variável). Nessa perspectiva, a variável focalizada nesta pesquisa é a expressão de $\mathrm{P} 4$, cujas variantes candidatas à sua realização são o tradicional pronome<nós> e a forma gramaticalizada <a gente>, ou seja, ambas as variantes possuem o mesmo valor no sentido de que exprimem a mesma noção no PB

\section{Os contínuos de variação linguística}

Para a compreensão do fenômeno da variação linguística no PB, BortoniRicardo (2004) propõe três linhas imaginárias ou contínuos, quais sejam, o de urbanização, o de oralidade-letramento e o de monitoração estilística. No presente trabalho adotaremos o contínuo de oralidade-letramento, por entendermos que é o que se aplica melhor ao fenômeno variável que abordaremos na mediação pedagógica: a coocorrência das variantes ou a seleção da forma de prestígio <nós> estão diretamente ligadas ao evento de comunicação: eventos de oralidade registram as duas, enquanto os marcados com o traço de [+letramento], sobretudo os situados nesse extremo do contínuo, selecionam a variante de prestígio. A proposta do contínuo de oralidadeletramento de Bortoni-Ricardo (2004) foi, portanto, o fundamento da metodologia que usamos para a distribuição dos gêneros textuais com os quais trabalhamos na mediação pedagógica a variação nós/ a gente, além do processo de retextualização.

\section{A gramaticalização de <a gente>}

A gramaticalização pertence ao universo das mudanças e variações linguísticas, sendo caracterizada quando um item lexical passa a desempenhar funções gramaticais ou um item gramatical vem a assumir funções mais gramaticais ainda. Para Lopes 
(2004), persiste na forma gramaticalizada <a gente> a concordância com verbo para a terceira pessoa do singular, mantendo-se até mesmo o caráter indeterminador e coletivo do nome primitivo, embora ative uma interpretação semântico-discursiva de $1^{a}$ pessoa $[+\mathrm{EU}]$.

Sobre essa alteração no plano sintático, a linguista Menon (1997) caracteriza as diversas fases de gramaticalização de <a gente〉, desde a locução nominal (LN) até chegar à categoria de pronome, conforme ilustra o quadro a seguir:

Quadro 1 - Fases da gramaticalização de <a gente>

\begin{tabular}{|c|c|c|c|c|}
\hline LN Plena $>$ & LN Especial $>$ & LN Invariável $>$ & pron. indet. > & pron. pessoal P1 \\
\hline gente $>$ & a gente $>$ & [a gente] $>$ & a gente $>$ & a gente $=$ nós, eu \\
\hline LNP & LNE & LNI & pr. indet. & $\begin{array}{c}\text { pr. pes. } 1 \text { pl. } ~ \\
\text { sing. }\end{array}$ \\
\hline
\end{tabular}

Fonte: Menon,1997, p.398

A gramaticalização de <a gente> contribuiu mais ainda para que o PB passasse de uma língua de sujeito nulo para uma língua de sujeito pleno, conforme descreve Duarte (1993).

\section{O que é retextualização?}

Como em uma das etapas da mediação pedagógica foi proposta a retextualização de um gênero a outro. Marcuschi (2001) afirma que a retextualização não é "um processo mecânico, mas demanda conhecimento de gênero, suporte, tornando-se uma operação complexa que interfere tanto no código quanto no sentido" (p. 46). O pesquisador postula que a oralidade e a escrita estão em um mesmo patamar de importância no processo comunicativo e principalmente na retextualização, em que o texto oral é transcodificado para a versão escrita.

Dessa forma, o pesquisador elencou várias operações para que se processe a retextualização, no entanto esclareceu que "para uma retextualização ser bem-sucedida, não é necessário que se efetivem todas as operações e, sobretudo, não necessariamente na ordem proposta" (p.76). Assim, as quatro primeiras operações seguem as regras de regularização e idealização, que almejam exclusão de marcas da oralidade e o acréscimo de elementos da escrita ou substituição por estes. As demais operações seguem as regras de transformação que, segundo o autor, são as que promovem mudanças mais significativas no texto-base, sendo as seguintes: as estratégias de 
substituição, seleção, acréscimo, reordenação e condensação, que irão interferir no tratamento estilístico do texto, sendo aquelas que propriamente caracterizam o processo de retextualização.

Dell'Isola (2007) concebe a retextualização como uma mudança de um gênero a outro gênero, ou seja, um texto original sofreria alterações ao mudar do gênero de partida para um outro tipo de gênero de destino, mantendo-se, no entanto, o cerne do conteúdo originador

\section{Metodologia da pesquisa}

A metodologia que utilizamos foi a de pesquisa-ação (cf. TRIPP, 2005), visto que nosso objeto de pesquisa era um problema (no caso o domínio de diferentes normas de escrita desde as situadas no polo de [+ oralidade] até as do polo de [+ letramento] do contínuo) em que os envolvidos no processo - professora-pesquisadora e alunos colaboraram para o alcance do objetivo. Tripp (2005) propõe que a pesquisa-ação seja vista como uma das muitas diferentes formas de investigação-ação, que consiste em toda tentativa continuada, sistemática e empiricamente fundamentada de aprimorar prática, produzindo, assim, informações e conhecimentos de uso mais efetivo, o que promove condições para ações e transformações de situações dentro da própria escola.

Da mesma forma, Kemmis e Mc Taggart (1988, apud ELIA; SAMPAIO, 2001), entendem a pesquisa-ação como uma

forma de investigação baseada em uma autorreflexão coletiva empreendida pelos participantes de um grupo social de maneira a melhorar a racionalidade e a justiça de suas próprias práticas sociais e educacionais, como também o seu entendimento dessas práticas e de situações onde essas práticas acontecem. A abordagem é de uma pesquisa-ação apenas quando ela é colaborativa. (KEMMIS; MC TAGGART,1988 apud ELIA; SAMPAIO, 2001, p. 248).

\section{Perfil da escola}

A pesquisa-ação foi realizada no Centro Integrado de Educação Pública (Ciep) Brizolão 053 Dr. Nelson dos Santos Gonçalves, que pertence à rede de ensino estadual do Rio de Janeiro. Localiza-se na periferia de Volta Redonda, cidade de médio porte do interior do estado, cuja economia se baseia em atividades comerciais, pequenas 
indústrias e, principalmente, em torno da Companhia Siderúrgica Nacional (CSN), um dos maiores complexos siderúrgicos do mundo ${ }^{3}$.

A escola situa-se em um complexo rodeado de bairros de classe média e favelas, portanto com uma diversidade grande no nível socioeconômico dos alunos. No entanto, a última prova Brasil realizada, em que é feita uma contextualização do nível socioeconômico dos alunos, posicionou a clientela do CIEP 053 no nível médio alto. ${ }^{4}$

No presente trabalho usamos como suporte teórico para alcançar nossos objetivos, o contínuo de oralidade-letramento proposto por Bortoni-Ricardo (2004), no qual organizamos os gêneros selecionados para a mediação pedagógica em atividades de retextualização segundo Marcuschi (2001). Essa retextualização envolveu textos escritos, todavia situados em diferentes pontos do contínuo: o relato de experiência, situado mais para a oralidade; o relatório, pertencente ao polo da escrita ou do letramento. Portanto, a retextualização abordada em nossa mediação pedagógica muito se aproximou das propostas de atividades desenvolvidas por Dell'Isola (2007), que partiram de um gênero a outro, porém dentro da mesma modalidade, no caso a escrita. Dessa maneira, os alunos foram levados a perceber o uso das variantes de P4 na passagem de um gênero com traços de oralidade a outro pertencente ao polo de letramento do contínuo.

Quanto às operações de retextualização elencadas por Marcuschi (2001), trabalhamos as que constituem regras de transformação, tendo em vista que o texto de partida foi uma produção escrita dos próprios alunos que deveria ser convertida em outro gênero também escrito, de maneira que não se tratava exatamente da passagem de uma sequência textual falada para o código escrito, o que seria contemplado nas quatro primeiras operações, enquadradas nas regras de regularização e idealização. Trabalhamos com a $7^{\mathrm{a}}$ e a $8^{\mathrm{a}}$ operações na mediação pedagógica aplicada. A $7^{\mathrm{a}}$ operação foi utilizada para que o tratamento estilístico dado ao relatório considerasse a seleção de novas estruturas sintáticas, novas opções léxicas, o que constitui a estratégia de substituição visando a uma maior formalidade, exigida pelo gênero textual de destino, que abdica de subjetividades, adjetivos e outras estruturas presentes no relato de experiência. $\mathrm{Na} 8^{\mathrm{a}}$ operação os alunos foram levados a ordenar os tópicos e reorganizar

${ }^{3}$ Conforme informações obtidas na própria página da empresa na internet, cujo link para consulta é o seguinte: http://www.csn.com.br/conteudo_pti.asp?idioma=0\&conta=45\&tipo=60023. Acesso em $23 \mathrm{de}$ abril de 2018.

${ }^{4}$ Segundo resultado da pesquisa da Prova Brasil enviado para a escola pelo MEC. 
a sequência do texto produzido, estruturando-o para adequar-se ao novo gênero, ou seja, condensaram ideias e mantiveram apenas o essencial que caberia no texto de chegada.

No decorrer das atividades de retextualização, seguimos com os alunos as tarefas propostas por Dell'Isola para esse processo, como a leitura; a compreensão do texto lido; a identificação do gênero; a retextualização; a conferência,(a verificação se o texto produzido atende às condições de produção e é fiel ao conteúdo do texto lido); a identificação das características do gênero-produto da retextualização; a reescrita, orientada pela conferência e pela identificação. Dessa forma, permitimos que os discentes refletissem sobre a linguagem e sobre a relação entre os gêneros e as estruturas sociais, conforme proposição da autora.

A mediação pedagógica proposta nesta pesquisa-ação contemplou sete etapas que transitou entre motivações, produções, correções, reescrituras e retextualização.

Após a conclusão das oficinas aplicadas na mediação pedagógica, realizou-se um concurso de redações cujos jurados pertenciam ao corpo docente da escola. Foram escolhidas as cinco melhores produções de relato de experiência retextualizadas para o gênero relatório.

Para a premiação, fez-se uma festa de encerramento do projeto, em que todos os alunos da turma puderam participar e ver, através de slides, desde as produções iniciais até as produções finais. No evento relembrou-se os momentos mais marcantes do projeto.

Nesse evento, houve a participação da equipe diretiva e pedagógica, bem como de alguns professores. Fizemos a leitura das redações dos três primeiros colocados, de maneira que os alunos não só se mostraram motivados e satisfeitos, como também se sentiram prestigiados.

\section{Conclusões}

Tendo em vista a mediação pedagógica aplicada, que buscou tratar da variação na expressão de P4 na perspectiva do contínuo oralidade-letramento proposto por Bortoni-Ricardo (2004), passamos a comparar os resultados obtidos, desde a produção inicial (diagnose) até a produção final para avaliação dos objetivos pretendidos nesta pesquisa. A trajetória das variantes foi estável em todo o contínuo, ou seja, houve a prevalência da canônica e pequena infiltração da variante inovadora, o que se explica pelo fato de se tratar de textos escritos. 
As produções dos alunos evidenciaram que a variante <a gente> já se apresenta também na escrita como concorrente de 〈nós>, em todos os pontos do contínuo uma vez que houve ocorrência até mesmo no gênero representativo do polo de [+ letramento], o que contraria a prática de escrita da sociedade letrada brasileira, que evita essa variante em gêneros representativos desse polo, constituindo um traço descontínuo, nos termos de Bortoni-Ricardo (2004). Embora a variante inovadora tenha aparecido nos relatórios dos alunos, sua ocorrência foi bem marginal, o que de certa forma aproximou a turma da prática da sociedade letrada brasileira, que prestigia a variante tradicional em eventos de letramento.

Em suma, mesmo analisando as três produções sem a reescritura, já se observou diferenças significativas entre os pontos do contínuo em que elas se situam. Na produção da diagnose, encontramos o uso híbrido das variantes na expressão de P4, compatível com as características da fala, inclusive com construções estigmatizadas envolvendo tanto <a gente> quanto <nós>:

(61) Nós se sentiu muito feliz[...] (S.M.B. - fem.)

(62) Depois de lá a gente fomos para o zoológico e depois fomos comer[...] (S.M.B. fem.)

Já na etapa em que os alunos produziram o relato de experiência sobre a visita ao asilo, o índice de frequência da variante < a gente> foi similar ao da produção inicial, porém com uma diferença qualitativa importante: a concordância verbal não canônica com <a gente> praticamente desapareceu, dando lugar ao uso da concordância verbal de prestígio, o que denota avanço em direção à proficiência desejada em relação ao objeto desta pesquisa. De fato, o brasileiro culto já emprega a variante inovadora para expressão de $\mathrm{P} 4$ em textos escritos não situados no polo de [+ letramento], como em crônicas, relatos de experiência, entre outros gêneros, porém não admite esse uso em textos escritos situados no polo de maior letramento do contínuo, como o relatório.

Por fim, na etapa em que produziram o relatório, percebeu-se uma preocupação maior dos alunos em usar uma linguagem característica desse gênero, ou seja, mais próxima de eventos de comunicação mediados pela escrita (cf. BORTONI-RICARDO, 2004), tendo havido o emprego semicategórico do pronome tradicional na expressão de P4. 
Dessa forma, podemos dizer que, por meio da mediação pedagógica aplicada, os alunos do $9^{\circ}$ ano do Ensino Fundamental (901) do Ciep 053 em VR demonstraram entender que podem usar na escrita representativa de eventos de comunicação não situados no polo de [+ letramento], como o relato de experiência, contrariando a praxe escolar tradicional que não admite o uso dessa variante em qualquer texto escrito. Por outro lado, também os mesmos alunos perceberam a necessidade de selecionar a variante canônica em gêneros de maior grau de letramento, como o relatório.

Os resultados obtidos nesta pesquisa mostraram a importância da ação das instituições de ensino não só para a aprendizagem da norma prescrita pela tradição gramatical, como também para a possibilidade de admitir e contextualizar o uso de outras variantes usadas pelos falantes. Tais variantes não devem ser discriminadas, sendo até mesmo desejáveis em determinados pontos do contínuo de oralidadeletramento, como é o caso da expressão de P4 representada por <a gente> que tem ampliado a cada dia sua abrangência, infiltrando-se até mesmo na escrita

\section{Considerações finais}

Esta pesquisa procurou investigar e analisar a ocorrência das variantes candidatas à representação de $\mathrm{P} 4$ em textos de alunos do $9^{\circ}$ ano do $\mathrm{EF}$, a partir da aplicação de uma mediação pedagógica que conduziu os estudantes a uma reflexão quanto ao uso dessas variantes, seja em textos com maior grau de letramento como o relatório, seja em textos mais próximos da oralidade como o relato de experiência.

O presente trabalho busca oferecer uma contribuição ao ensino de Língua Portuguesa no que diz respeito à abordagem da variação linguística em sala de aula a partir de atividades sequencialmente planejadas com vistas a superar duas práticas docentes opostas no tratamento desse fenômeno: uma que ignora o pronome <a gente>, rotulando-o como inadequado a toda forma de expressão escrita; outra que se isenta de qualquer descrição gramatical nas aulas de Língua Portuguesa. Por meio da mediação pedagógica aplicada, pudemos perceber que é possível apresentar os contextos de ocorrência de ambas as variantes sem discriminar as diferentes variedades da língua, realizando dessa forma a abordagem da variação linguística conforme as orientações oficiais para o ensino (PCN e BNCC).

O levantamento das variantes usadas para a representação de P4 em textos produzidos pelos alunos ao longo do contínuo de oralidade-letramento foi feito a partir 
do relato de experiência até a tessitura do relatório. Ao mesmo tempo, os alunos puderam, de forma efetiva e prática, observar a distinção dos diferentes polos e foram levados a reconhecer os contextos de uso das variantes em cada ponto do contínuo, de modo a desenvolverem a habilidade de transitar de textos representativos do polo de [+ oralidade] aos do polo de [+ letramento], o que acabou por confirmar a hipótese formulada para esta pesquisa.

Os dados colhidos na diagnose já revelavam que os alunos do $9^{\circ}$ ano do EF já tinham uma percepção dos usos linguísticos prestigiados na escrita, haja vista a alta frequência da variante canônica e de sujeito nulos, no entanto havia uma mistura de usos tradicionais e inovadores na expressão de $\mathrm{P} 4$, de modo que demonstraram insegurança na hora de escolher qual variante deveriam usar em suas produções posteriores. Entretanto, esse problema foi amplamente trabalhado no transcorrer da mediação pedagógica com vistas à resolução e, ao final, os alunos se apropriaram da capacidade de adequação e adquiriram maior segurança no uso das variantes a depender da exigência dos gêneros textuais determinada pelo ponto do contínuo oralidadeletramento em que se situam.

A proposta pretendida nesta pesquisa em não se ater a um ensino tradicional e preconceituoso foi a força motriz durante todo o percurso da pesquisa e aplicação da mediação pedagógica. Evidenciou-se que o uso de <a gente> é amplo até nos meios acadêmicos no que tange à oralidade, com presença também na escrita não situada no polo de letramento, sendo evitado apenas em textos escritos da cultura letrada, o que mostrou a utilidade de trabalhar com o contínuo oralidade-letramento de BortoniRicardo (2004). Assim, nosso alvo não foi discriminar uma variante em benefício de outra, mas sim conscientizar o discente sobre a distribuição do uso de ambas tanto na modalidade oral quanto na escrita do PB.

Percebemos que os discentes se apropriaram desse conhecimento com base no que aprenderam no decorrer da mediação pedagógica e também no conhecimento linguístico adquirido ao longo da vida escolar. Nossa meta de mostrar-lhes as diferentes possibilidades de realização de $\mathrm{P} 4$ em sua forma canônica e variacional em textos de diferentes pontos do contínuo culminou com um saldo positivo e satisfatório. Os alunos evidenciaram que o relato de experiência pode comportar as duas variantes, ao contrário do gênero relatório, que seleciona apenas o pronome canônico para expressão de primeira pessoa do plural. Assim sendo, aferimos que os estudantes alcançaram os objetivos propostos por esta pesquisa no decorrer das atividades, tanto em relação à 
estrutura de cada gênero textual estudado, quanto em relação à representação de P4, reconhecendo o uso de cada variante nos diferentes gêneros.

Deste modo, esperamos que este trabalho tenha utilidade aos profissionais e discentes que objetivam um ensino que aborde a variação linguística inserida dentro do dinamismo de nossa língua em suas variadas normas. Todo falante deve ter o conhecimento necessário para transitar entre as diferentes variedades, de modo a atender aos diversos eventos comunicativos, mediados quer pela fala, quer pela escrita.

AGRADECIMENTO: À Coordenação de Aperfeiçoamento de Pessoal de Nível Superior -Brasil (CAPES) - pelo apoio financeiro a esta pesquisa. - Código de Financiamento 001.

\section{REFERÊNCIAS}

ALKMIM, T. M. Sociolinguística - Parte I. In: MUSSALIM, F.; BENTES, A. C. (ed.). Introdução à Linguística. São Paulo: Cortez, 2001

AMARAL, H. Prêmio escrevendo o futuro relato de experiência professores semifinalistas. Disponível em:

https://www.escrevendoofuturo.org.br/EscrevendoFuturo/arquivos/2169/orientacoes_rel ato_e_experiencia_2006.pdf. Acesso em: 11 jan. de 2019

AZEREDO, J. C. de Gramática Houaiss da língua portuguesa. 2. ed. São Paulo: Publifolha, 2008.

BAGNO, M. Gramática pedagógica do português brasileiro. São Paulo: Parábola Editorial, 2011.

BECHARA, E. Moderna gramática portuguesa. 37. ed. rev., ampl. e atual. conforme o novo Acordo Ortográfico. Rio de Janeiro: Nova Fronteira, 2007.

BELTRÃO; O.; BELTRÃO M. Correspondência linguagem e comunicação: Oficial, Empresarial, Particular. São Paulo: Atlas, 23. Ed. $5^{\circ}$ Cap. p. 125-129, 2005.

BORGATTO, A. M. T.; BERTIN, T. C. H.; MARCHEZI, V. L de C. Projeto Teláris: Português: Ensino. 2. ed. São Paulo. Ática, 2015.

BORTONI-RICARDO, S. M. Educação em língua materna: a sociolinguística na sala de aula. São Paulo: Parábola, 2004.

BRASIL.Ministério da Educação.1998. Parâmetros Curriculares Nacionais de Língua Portuguesa. Disponível em: http://portal.mec.gov.br/seb/arquivos/pdf/portugues.pdf. Acesso em: 05 mar. 2018. 
BRASIL. Lei $\mathrm{n}^{\circ}$ 13.500, de 25 de junho de 2014. Aprova o Plano Nacional de Educação - PNE e dá outras providências. Disponível em: Acesso em: 10 set. 2016.

BRASIL. Ministério da Educação. Base Nacional Comum Curricular - BNCC $3^{\mathrm{a}} \mathrm{e}$ última versão. Brasília, DF, 2017

CASTILHO, A. T. de. Nova gramática do português brasileiro. São Paulo: Contexto, 2010

COAN, M.; FREITAG, R. M. Sociolinguística variacionista: Pressupostos teóricos metodológicos e propostas de ensino. In: Domínios de Lingu@gem, Uberlândia, v. 4, n. 2, 2. sem. 2010. pp. 173194. Disponível em:

http://www.seer.ufu.br/index.php/dominiosdelinguagem/article/view/1618/6863. Acesso em: 27 fev. de 2018.

COELHO, I. L.; GÖRSKI, E. M.; NUNES de SOUZA, C. M. N.; MAY, G. H. Para conhecer sociolinguística. São Paulo: Contexto, 2015.

COSTA, C. L.; MARCHETTI, G.; SOARES, J. J. B. Para Viver Juntos: Português. 3 ed. São Paulo: Ed. SM,2012

CUNHA, C. F.; Cintra, L. Nova gramática do português contemporâneo. Rio de Janeiro: Nova Fronteira, 1985.

DELL'ISOLA, R.L.P. Retextualização de gêneros escritos. Rio de Janeiro: Lucerna.,2007.

DUARTE, M. E. Do pronome nulo ao pronome pleno: a trajetória do sujeito no português do Brasil. In: ROBERTS, I., KATO, M. A.(orgs.) Português Brasileiro: uma viagem diacrônica. Campinas: Ed. da UNICAMP. p.107-128, 1993.

ELIA, M. F., SAMPAIO, F. F. Plataforma Interativa para Internet: Uma proposta de Pesquisa-Ação a Distância para professores, Anais do XII Simpósio Brasileiro de Informática na Educação, 102-109, 2001.

FARACO, C. A. Norma culta Brasileira: desatando alguns nós. São Paulo: Parábola Editorial, 2008.

FIGUEIREDO, L. de; BALTHASAR, M.; GOULART, S. Singular \& Plural: Leitura, Produção e Estudos. 2. ed. São Paulo: Moderna, 2015.

FREIRE, G.C. Ensino de morfossintaxe: das pesquisas acadêmicas aos livros didáticos de português. In: COELHO, F. A; SILVA, J. E. N. (orgs.) Ensino de língua portuguesa: teorias e práticas. Rio de Janeiro: Gramma, 2018. pp. 125-143.

KOCHE, V. S. et al. Estudo e produção de texto: gêneros textuais do relatar, narrar e descrever. Petrópolis: Editora Vozes, 2012. 
LOPES, C.R.S. Nós e a gente no português falado culto do Brasil. Rio de Janeiro: Faculdade de Letras/UFRJ. Dissertação de Mestrado em Língua Portuguesa.

Universidade Federal do Rio de Janeiro, Rio de Janeiro, 1993.

LOPES, C.R.S. A inserção de 'a gente' no quadro pronominal do português.

Frankfurt/Madri: Vervuert/Iberoamericana, vol. 18, 2003.

LOPES, C.R.S. A gramaticalização de a gente em português em tempo real de longa e de curta duração: retenção e mudança na especificação dos traços intrínsecos. Fórum Linguístico, v. 4, nº1. Florianópolis, julho de 04. pp. 47-80, 2004.

LOPES, C.R.S. A gramaticalização de a gente em português em tempo real de longa e de curta duração: retenção e mudança na especificação dos traços intrínsecos. Fórum Linguístico, v. 4, n. 1, p. 47-80, 2007.

MACHADO, M. S. Sujeitos pronominais "nós" e "a gente": variação em dialetos populares do norte fluminense. Dissertação (Mestrado em Língua Portuguesa) Universidade Federal do Rio de Janeiro, Rio de Janeiro, 1995.

MAIA, F. P. S. A variação "nós" / "a gente" no dialeto mineiro: investigando a transição. 2003. Dissertação (Mestrado em Estudos Linguísticos) - Universidade Federal de Minas Gerais, Belo Horizonte, 2003.

MARCUSCHI, L.A. Da Fala para a Escrita: Atividades de Retextualização. São Paulo: Cortez, 2001.

MEDEIROS, João Bosco. Correspondência: técnicas de Comunicação criativa. $18^{a}$ ed. São Paulo: Atlas, 2006.

MENDONÇA, A. K. Nós e a gente em Vitória: análise sociolinguística da fala capixaba. 2010. Dissertação (Mestrado em Estudos Linguísticos) - Universidade Federal do Espírito Santo, Vitória, 2010.

MENON, O.P.S. A gente, eu, nós: sintomas de uma mudança em curso no Português do Brasil? In: Anais do II ELFE - Encontro Nacional sobre Língua Falada e Escrita. Maceió, p. 396-402, 1997.

NEVES, M. H. M. Gramática de usos do português. São Paulo: Ed. UNESP, 2011.

OLIVEIRA, J. B. M. de. Concepções de escrita, texto e gênero textual em relatos de aula de língua materna. Revista Virtual de Estudos da Linguagem - ReVEL. V. 2, n. 2, março de. ISSN 1678- 8931 [www.revel.inf.br], 2004.

OMENA, N. P. A referência variável da primeira pessoa do discurso no Plural. In: NARO, A. J. et alii: Relatório Final de Pesquisa: Projeto Subsídios do Projeto Censo à Educação, Rio de Janeiro, UFRJ, 1986.

OMENA, N. P As influências sociais na variação entre nós e a gente na função de sujeito. In: OLIVEIRA E SILVA, G. M.; SCHERRE, M. M. P. Padrões 
Sociolinguísticos: análises de fenômenos variáveis do português falado na cidade do Rio de Janeiro. Rio de Janeiro: Tempo Brasileiro, p. 309-323, 1996

OMENA, N. P A referência à primeira pessoa do plural: variação ou mudança? In: PAIVA, M. C.; DUARTE, M. E. L. (Org.). Mudança linguística em tempo real. Rio de Janeiro: Contracapa, 2003.

PEREIRA, C. S.; BARROS, F. P.; MARIZ, L. Universos: Língua Portuguesa. $3^{\text {a }}$. ed. São Paulo: Ed.SM, 2015.

RIO DE JANEIRO. Secretaria Estadual de Educação. Reorientação Curricular de Língua Portuguesa para o Ensino Médio e Ensino Fundamental $2^{\circ}$ segmento: versão definitiva. Livro I. Linguagens e Códigos. Rio de Janeiro, 2006.

ROCHA, F. C. F. A alternância nos pronomes pessoais e possessivos do português de Belo Horizonte. Dissertação de Mestrado em Linguística e Língua Portuguesa, Belo Horizonte, Faculdade de Letras/PUC-MG, 2009

ROCHA LIMA, C. H. Gramática normativa da língua portuguesa.J. Olympio, 2008 [1972].

SILVA, C. de O.; SILVA, E. G.de O.; ARAÚJO, L. A. M.; OLIVEIRA, T. A. Tecendo Linguagens. 4 eds. IBEP, 2015

TRAVAGLIA, L.C. Da distinção entre tipos, gêneros e subtipos de textos. Estudos linguísticos, 30: 1-6, 2001

TRIPP, D. Pesquisa-ação: uma introdução metodológica. Educação e Pesquisa [periódico na Internet]. Set-Dez. Acesso em 5 de abr. 2018. Disponível em http://www.scielo.br/ pdf/ep/v31n3/a09v31n3.pdf., 2005

VIANNA, J. B. S. Semelhanças e diferenças na implementação de a gente em variedades do português. Tese (Doutorado em Letras Vernáculas) - Universidade Federal do Rio de Janeiro, Rio de Janeiro,235f, 2011

VIEIRA, S. R.; FREIRE, G. C. Variação morfossintática e ensino de português. In: MARTINS, M. A. et al. (orgs.) Ensino de português e Sociolinguística. São Paulo: Contexto, pp. 81-114, 2014

\section{Como referenciar este artigo}

CUNHA, C. C. P. M.; SILVA, M. P. M. da. Variação na expressão da primeira pessoa do plural em textos de alunos do ensino fundamental: uma proposta pedagógica. Rev. EntreLínguas, Araraquara, v. 5, n. 2, p. 394-417, jul./dez. 2019. E-ISSN: 2447-3529. DOI: $10.29051 /$ el.v5i2.12932

Submetido em: 15/03/2019

Revisões requeridas: 18/04/2019

Aprovado em: 25/05/2019

Publicado em: 01/10/2019 